\title{
Adoption and Reasons for Withdrawal of ICH Q1F Guidelines
}

\author{
Siddharth Jadeja ${ }^{1}$, Girish pai kulyadi ${ }^{2}$ and Muddukrishna Badamane Sathyanarayana ${ }^{1 *}$ \\ 'Department of Pharmaceutical Quality Assurance, Manipal College of Pharmaceutical Sciences, Manipal-576104, Karnataka, INDIA. \\ 2Department of Pharmaceutics, Manipal College of Pharmaceutical Sciences, Manipal-576104, Karnataka, INDIA.
}

\begin{abstract}
ICH Q1 F guideline provided astability data package for the registration applications of drug substance and drug product in Climatic Zones III (hot and dry) and IV (hot and humid). These guidelines were adopted by the $\mathrm{ICH}$ in February 2003 and subsequently implemented in the $\mathrm{ICH}$ regions. Due to some reasons the guidelines were withdrawn. This review article describes the development of the concept of the climatic zones, the introduction of the guideline Q1F, its adoption, objections to these guidelines, its withdrawal and reasons for the withdrawal and its alaternative that was proposed.
\end{abstract}

Key words: Guidelines, ICH, Q1F, Stability, Withdrawal.
Correspondence:

Muddukrishna Badamane Sathyanarayana,

Department of Pharmaceutical Quality Assurance,

Manipal College of Pharmaceutical Sciences,

Manipal-576104, Karnataka, INDIA.

Phone no: +919483932250

E-mail: krishna.mbs@manipal.edu

DOI : 10.5530/jyp.2016.4.31

\section{INTRODUCTION}

Stability studies of a drug substance or a drug product are carried out to check how its properties change with time under the influence of various environmental factors like temperature, humidity and light. Shelf life of a drug product and the retest period of the drug substance can be estimated with the help of stability studies. The guidelines for the stability testing of drug substance and drug product are provided by $\mathrm{ICH}$ (International Conference on Harmonization), WHO and many other regional authorities. These guidelines provide the information that is to be submitted in registration applications for new chemical entity and associated drug products. ${ }^{3}$

\section{The development of the concepts of zones}

In order to reduce the amount of long-term storage testing required, it was necessary to reduce the number of different long-term testing |condition to a sufficient extent. This approach was first time proposed by Paul Schumacher in year 1972 and Wolfgang Grimm in 1986 and again in 1998 when they defined four different long-term storage conditions keeping the climatic conditions into consideration of the target markets. The entire globe was divided into four different climatic zones and this concept was described in various regulatory guidelines and pharmacopoeias. This became an established standard in developing finished pharmaceutical products. ${ }^{9}$

ICH guideline Q1A (1993) that provides guideline for stability testing of new drug substances and products focused mostly on the ICH zones (I and II) at the time of its implementation. ${ }^{1}$

The first WHOstability guidelines were initiated in the year 1988 and published in 1996. These guidelines included the non-ICH regions as well (i.e. zone III and zone IV) along with the ICH regions. These guidelines were meant to focus on testing the stability of pharmaceutical products containing well-established drug substances in conventional dosage forms and generics. Its concept was mainly based on the climatic zones. The entire globe was divided into 4 different climatic zones.

I. Zone I: Temperate: Kinetic average temperature $21^{\circ} \mathrm{C}$ and $45 \%$ of annual average relative humidity.

II. Zone II: Mediterranean: Kinetic average temperature $25^{\circ} \mathrm{C}$ and $60 \%$ of annual average relative humidity.
III. Zone III: Hot and dry: Kinetic average temperature $30^{\circ} \mathrm{C}$ and $35 \%$ of annual average relative humidity.

IV. Zone IV: Hot and humid: Kinetic average temperature $30^{\circ} \mathrm{C}$ and $70 \%$ of annual average relative humidity. ${ }^{9}$

Countries in various climatic Zones: The distribution of the countries in various climatic zones are as per shown in Table $1 .{ }^{1}$

\section{Stability storage conditions as per ICH and WHO guidelines}

\section{ICH Q1A (Zones I and II)}

Long term storage condition: $25 \pm 2{ }^{\circ} \mathrm{C} / 60 \pm 5 \% \mathrm{RH}$

Intermediate storage condition: $30 \pm 2^{\circ} \mathrm{C} / 60 \pm 5 \% \mathrm{RH}$

Accelerated stability testing condition: $40 \pm 2^{\circ} \mathrm{C} / 75 \pm 5 \% \mathrm{RH}$

WHO (Zones III and IV)

Long term: $30 \pm 2^{\circ} \mathrm{C} / 35 \pm 5 \% \mathrm{RH}$ (Zone III)

$30 \pm 2^{\circ} \mathrm{C} / 70 \pm 5 \% \mathrm{RH}$ (Zone IV)

Accelerated: $40 \pm 2^{\circ} \mathrm{C} / 75 \pm 5 \% \mathrm{RH}$

\section{The start of politics on long-term stability storage conditions}

In July 2000 Dr. Nick Turner sent a paper to WHO on behalf of the ICH expert working group Q1(stability). The paper mainly focused on the rationale for the stability conditions for the climatic zone IV (hot and humid). He suggested that the storage condition of $30 \pm 2^{\circ} \mathrm{C} / 60 \pm 5 \%$ $\mathrm{RH}$ would be sufficient for the climatic zone IV but WHO recommended the storage condition of $30 \pm 2^{\circ} \mathrm{C} / 70 \pm 5 \% .^{1}$

WHO accepted the plea on majority recommendations by the experts and finalized the storage condition of $30 \pm 2^{\circ} \mathrm{C} / 60 \pm 5 \% \mathrm{RH}$ for long term stability studies for zone IV countries.

After this alteration in the storage condition, the guideline Q1A was termed as Q1A(R).

\section{Objection by African region}

The limits of these newly proposed storage conditions were $30^{\circ} \mathrm{C} / 55 \%$ $\mathrm{RH}$ to $30^{\circ} \mathrm{C} / 65 \% \mathrm{RH}$ as per Q1A(R), but the condition of $30^{\circ} \mathrm{C} / 55 \% \mathrm{RH}$ 
is very dry for coastal regions of Africa, hence this storage condition had to be reconsidered by ICH and WHO.

After considering this, ICH and WHO came to a conclusion that, the intermediate storage condition for Zone I and II regions for general case and the long term storage condition for Zone IV region for general case were kept as $30 \pm 2^{\circ} \mathrm{C} / 65 \pm 5 \% \mathrm{RH}$. This satisfied the need of the African countries since the limit of relative humidity was increased. ${ }^{1}$

The following changes were made: as a result, it was decided to introduce a new stability guideline for the countries belonging to climatic zone III and IV which will satisfy the needs proposed by these countries and name it as Q1F.

After the adoption of Q1F guidelines, following changes were made in the previous guideline $\mathrm{Q} 1 \mathrm{~A}(\mathrm{R})$ regarding storage conditions and the guideline was termed as Q1A(R2) in February 2003.

1. The intermediate storage condition was changed from $30^{\circ} \mathrm{C} \pm$ $2^{\circ} \mathrm{C} / 60 \% \mathrm{RH} \pm 5 \% \mathrm{RH}$ to $30^{\circ} \mathrm{C} \pm 2^{\circ} \mathrm{C} / 65 \% \mathrm{RH} \pm 5 \% \mathrm{RH}$ in the general case for drug substance and drug product.

2. $30^{\circ} \mathrm{C} \pm 2{ }^{\circ} \mathrm{C} / 65 \% \mathrm{RH} \pm 5 \% \mathrm{RH}$ was considered a suitable alternative long-term storage condition to $25^{\circ} \mathrm{C} \pm 2{ }^{\circ} \mathrm{C} / 60 \% \mathrm{RH} \pm 5 \%$ in the general case for drug substance and drug product. ${ }^{3}$

\section{Introduction of ICH Q1F guideline}

Q1A(R2) provided the guideline for stability testing of pharmaceutical drug substances or product for application in other countries along with Europe, Japan and USA, which are present in climatic zone I and II. For the countries present in climatic zone III and IV this parent guideline could be useful, except the storage conditions.

The World Health Organization (WHO) published a guideline with the name 'Stability testing of pharmaceutical product containing well established drug substance in conventional dosage forms' and this guideline was updated in the $37^{\text {th }}$ meeting of WHO expert committee which was held in Geneva (October 2001). This guideline provided the stability testing recommendations along with storage conditions for all four climatic zones.

In guideline $\mathrm{Q} 1 \mathrm{~F}$ the stability testing recommendations were mentioned keeping the WHO and ICH Q1A(R2) in mind. In order to harmonize with the long-term storage condition for zone III and IV regions ICH had to change the intermediate storage condition in general case to $30^{\circ} \mathrm{C}$ $\pm 2^{\circ} \mathrm{C} / 65 \% \mathrm{RH} \pm 5 \% \mathrm{RH}$. This new established storage condition was also an alternative to $25 \pm 2{ }^{\circ} \mathrm{C} / 60 \pm 5 \% \mathrm{RH}$ as a long-term storage condition in parent guideline for general case.

came into existence in 2003. The parent guideline was considered applicable to climatic zones III and IV except the long-term storage conditions, which were included in this Q1F guideline.

Storage condition for general case as per Q1F: Long-term storage condition: $30^{\circ} \mathrm{C} \pm 2{ }^{\circ} \mathrm{C} / 65 \% \mathrm{RH} \pm 5 \% \mathrm{RH}$ (For 12 months)

Accelerated storage condition: $40^{\circ} \mathrm{C} \pm 2{ }^{\circ} \mathrm{C} / 75 \% \mathrm{RH} \pm 5 \% \mathrm{RH}$ (For 6 months)

\section{ASEAN Objection to the revised stability guidelines}

Association of South East Asian Nations(ASEAN) comprises of countries like Cambodia, Indonesia, Brunei Darussalam, Lao PDR (Laos), Malaysia, Philippines, Myanmar, Singapore, Thailand and Vietnam. ${ }^{1}$ These countries are situated in climatic zone IV (hot and humid). Regulators and experts from ASEAN countries met with WHO and experts from International Federation of Pharmaceutical Manufacturers and Association on regular basis to discuss if the testing condition provided by the WHO and $\mathrm{ICH}$ guideline are appropriate for countries which are having such vast area and the climatic conditions present are above the average relative humidity and temperature used to characterize zone IV. After several discussions, a meeting was held in Jakarta on 12-13 January 2004. In this meeting, it was concluded that the testing conditions described in WHO and ICH guideline did not adequately address the climatic conditions that is prevailing in majority of countries of ASEAN.

ASEAN proposed a change in the current guideline. They proposed that instead of $30^{\circ} \mathrm{C} \pm 2{ }^{\circ} \mathrm{C} / 65 \% \mathrm{RH} \pm 5 \% \mathrm{RH}$ condition in long term storage, the condition should be changed to $30^{\circ} \mathrm{C} \pm 2^{\circ} \mathrm{C} / 75 \% \mathrm{RH} \pm 5 \%$ $\mathrm{RH}$ or should keep the previous storage condition of $30^{\circ} \mathrm{C} \pm 2{ }^{\circ} \mathrm{C} / 70 \%$ $\mathrm{RH} \pm 5 \%$.

\section{Reason for this change}

ASEAN believed that the testing should be performed on more stressful condition rather than less stressful condition so that if any error occurs that will not harm the patient and will increase the chances of identifying the factor that could cause any particular stability problem.

Attempts by WHO for harmonization: ASEAN, ICH and WHO and other interested parties held a meeting in December 2004. The following recommendations were made in the meeting.

1. To revert the long-term storage condition for the regional climatic zone IV to $30^{\circ} \mathrm{C} \pm 2{ }^{\circ} \mathrm{C} / 70 \% \mathrm{RH} \pm 5 \%$.

2. To keep $30^{\circ} \mathrm{C} \pm 2^{\circ} \mathrm{C} / 75 \% \mathrm{RH} \pm 5 \%$ as long-term stability testing condition for zone IV.

3. To include a new climatic zone IV(b) that consists of hot and humid areas $\left(30^{\circ} \mathrm{C} / 75 \% \mathrm{RH}\right)$ and the zone IV was termed as zone $\operatorname{IV}(\mathrm{a})\left(30^{\circ} \mathrm{C} / 65 \% \mathrm{RH}\right) .^{10}$

March 2005 was the last date to receive the feedbacks. After all these attempts also no proper solution to this problem was found.

Current Status: A suggestion to split the current climatic zone IV (hot and humid) into two zones was made in the fortieth meeting of WHO Expert committee on specifications for pharmaceutical preparations held in Geneva in October 2005.

- Zone IV(a) (30 degrees Celsius and 65\% relative humidity); and

- Zone IV(b) (30 degrees Celsius and 75\% relative humidity)

It was agreed that each individual member state of zone IV would need to indicate whether the region comes inzone IV(a) or zone IV(b). ${ }^{10}$

\section{Rise in regional expectation}

The guideline Q1F was adopted by ICH in February 2003. However, various regions in the climatic zone IV had their own expectation as far as the storage conditions were concerned. Therefore, they made necessary alteration in their own stability guidelines.

Long-term storage conditions recommended in some of the regional guidelines are as follows:

1. ASEAN Guideline on stability study of the drug product: The testing storage condition as per the ASEAN stability guidelines introduced in July 2004 are as per the Table $2:^{4}$

2. Regional guideline for the WHO East Mediterranean Region: The storage conditions to be followed as per the regional stability guideline of EMR is as in Table 3: ${ }^{5}$

3. Mexican Standard NOM-073-SSA1-2005, Stability of Drugs and Medicine. Table 4 . $^{7}$

4. Productos Farmaceuticos. Estudios De Estabilidad Medicamentos Para USO Humano: This is the regulatory guideline for the stability testing of the pharmaceuticals in Central America.

The storage conditions for general case as per this guidelines are as per Table $5:^{11}$

5. Guideline for stability testing of new drug substance and products by SFDA (The Saudi Food and Drug Authority): 
Table 1: Distribution of countries into four different climatic zones.

\begin{tabular}{|c|c|c|}
\hline Region & Zone I and II countries & Zone III and IV countries. \\
\hline Europe & All countries & ---1---- \\
\hline America & Argentina, Bolivia, Chile, Canada, Mexico, Peru, Uruguay, USA & $\begin{array}{c}\text { Barbados, Belize, Costa Rica, Dominican republic, Ecuador, EI } \\
\text { Salvador, Guatemala, Guyana, Haiti, Brazil, Honduras, Columbia, } \\
\text { Cuba, Nicaragua, Dutch Antilles, Panama, Paraguay, Puerto Rico, } \\
\text { Venezuela, Jamaica. }\end{array}$ \\
\hline Asia & $\begin{array}{c}\text { Afghanistan, Armenia, Azerbaijan, China, Georgia, Iran, Israel, Japan, } \\
\text { Kazakhstan, Kirghizia, Korea, Lebanon, Nepal, Syria, Tadzhikistan, } \\
\text { Turkey, Turkmen, Uzbekistan. }\end{array}$ & $\begin{array}{l}\text { Bahrain, Hong Kong, India, Indonesia, Iraq, Jordan, Qatar, Kuwait, } \\
\text { Laos, Malaysia, Maldives Islands, Oman, Pakistan, Philippines, } \\
\text { Saudi Arabia, Myanmar, Singapore, Sri Lanka, Taiwan, Kampuchea, } \\
\text { Thailand, United Arab Emirates, Vietnam, Yemen, , Bangladesh. }\end{array}$ \\
\hline Africa & $\begin{array}{l}\text { Egypt, Libya, Morocco, Ruanda,Algeria, South Africa, Zambia, } \\
\text { Namibia, Zimbabwe. }\end{array}$ & $\begin{array}{l}\text { Angola, Ethiopia, Benin, Botswana, Burundi, Djibouti, Ivory coast, } \\
\text { Gabon, Ghana, Guinea, Cameroon, Longo, Madagascar, Malawi, Mali, } \\
\text { Mauritania, Liberia, Niger, Nigeria, Senegal, Sierra Leone, Somalia, } \\
\text { Sudan, Gambia, Tanzania, Togo, Chad, Uganda, Central African } \\
\text { Republic, Kenya, Zaire. }\end{array}$ \\
\hline Australian & Australia, New Zealand. & $\begin{array}{c}\text { Marshall Islands, New Caledonia, Papua-New Guinea, Samoa, Tonga, } \\
\text { Fiji. }\end{array}$ \\
\hline
\end{tabular}

Table 2: Storage condition as per ASEAN guidelines

\begin{tabular}{cc}
\hline STUDY/TYPE OF CONTAINER & STORAGE CONDITION \\
\hline $\begin{array}{c}\text { Long term (for products in primary } \\
\text { containers semi-permeable to water vapor) } \\
\text { Long term (for products in primary } \\
\text { containers impermeable to water vapor) } \\
\text { Accelerated } \\
\text { Stress testing }\end{array}$ & $30^{\circ} \mathrm{C} \pm 2^{\circ} \mathrm{C} / 75 \% \mathrm{RH} \pm 5 \% \mathrm{RH}$ \\
\end{tabular}

Table 3: Storage condition as per guideline for the WHO EMR

\begin{tabular}{ccc}
\hline Study & Storage condition & $\begin{array}{c}\text { Minimum time period covered by } \\
\text { data at submission }\end{array}$ \\
\hline Long term & $25^{\circ} \mathrm{C} \pm 2^{\circ} \mathrm{C} / 60 \% \mathrm{RH} \pm 5 \% \mathrm{RH}$ or & 12 months \\
& $30^{\circ} \mathrm{C} \pm 2^{\circ} \mathrm{C} / 65 \% \mathrm{RH} \pm 5 \% \mathrm{RH}$ & \\
Intermediate & $30^{\circ} \mathrm{C} \pm 2^{\circ} \mathrm{C} / 65 \% \mathrm{RH} \pm 5 \% \mathrm{RH}$ & 6 months \\
Accelerated & $40^{\circ} \mathrm{C} \pm 2^{\circ} \mathrm{C} / 75 \% \mathrm{RH} \pm 5 \% \mathrm{RH}$ & 6 months \\
\hline
\end{tabular}

Table 4: Storage condition as per mexican regional guideline

\begin{tabular}{ccc}
\hline Type of study & Storage conditions & Minimal period \\
\hline $\begin{array}{c}\text { Accelerated stability } \\
\text { Intermediate } \\
\text { stability }\end{array}$ & $40^{\circ} \mathrm{C} \pm 2^{\circ} \mathrm{C} / 75 \% \pm 5 \% \mathrm{RH}$ & 6 months \\
$30^{\circ} \mathrm{C} \pm 2^{\circ} \mathrm{C} / 65 \% \pm 5 \% \mathrm{RH}$ & 6 months \\
Long-term stability & $25^{\circ} \mathrm{C} \pm 2^{\circ} \mathrm{C} / 60 \% \pm 5 \% \mathrm{RH}$ & 12 months \\
& or \\
& $30^{\circ} \mathrm{C} \pm 2^{\circ} \mathrm{C} / 65 \% \pm 5 \% \mathrm{RH}$ & \\
\hline
\end{tabular}

Table 5: Storage conditions as per the regulatory guideline of central america

\begin{tabular}{cc}
\hline Type of product & Storage condition \\
\hline Solid dosage form & $40^{\circ} \mathrm{C} \pm 2{ }^{\circ} \mathrm{C} / 75 \% \pm 5 \% \mathrm{RH}$ \\
For liquid and semisolid dosage forms & $40^{\circ} \mathrm{C} \pm 2{ }^{\circ} \mathrm{C}$ \\
\hline
\end{tabular}


Table 6: General storage condition as per SFDA guidelines

\begin{tabular}{ccc}
\hline Study & Storage condition & $\begin{array}{c}\text { Minimum time period covered by data at } \\
\text { submission }\end{array}$ \\
\hline Long-term & $30^{\circ} \mathrm{C} \pm 2^{\circ} \mathrm{C} / 65 \% \mathrm{RH} \pm 5 \% \mathrm{RH}$ & 12 months \\
Accelerated & $40^{\circ} \mathrm{C} \pm 2^{\circ} \mathrm{C} / 75 \% \mathrm{RH} \pm 5 \% \mathrm{RH}$ & 6 months \\
\hline
\end{tabular}

Table 7: Summary of the implementation of the stability guidelines

\begin{tabular}{|c|c|c|c|c|}
\hline Year & Guideline & Climatic zone & $\begin{array}{l}\text { Long term storage } \\
\text { condition }\end{array}$ & $\begin{array}{l}\text { Intermediate storage } \\
\text { condition }\end{array}$ \\
\hline 1993 & ICH Q1A & I and II & $25^{\circ} \mathrm{C} / 60 \% \mathrm{RH}$ & $30^{\circ} \mathrm{C} / 60 \% \mathrm{RH}$ \\
\hline 1996 & WHO guideline & III and IV & $30^{\circ} \mathrm{C} / 70 \% \mathrm{RH}$ & ---------------- \\
\hline 2001 & WHO Rev 1 & III and IV & $30^{\circ} \mathrm{C} / 65 \% \mathrm{RH}$ & \\
\hline 2003 & ICH Q1A(R2) & I and II & $\begin{array}{l}25^{\circ} \mathrm{C} / 60 \% \mathrm{RH} \\
30^{\circ} \mathrm{C} / 65 \% \mathrm{RH}\end{array}$ & $30^{\circ} \mathrm{C} / 65 \% \mathrm{RH}$ \\
\hline 2003 & ICHQ1F & III and IV & $30^{\circ} \mathrm{C} / 75 \% \mathrm{RH}$ & \\
\hline $2004 / 2005$ & ASEAN & IV & $30^{\circ} \mathrm{C} / 75 \% \mathrm{RH}$ & \\
\hline 2005 & WHO Rev.2 & III and IVaIVb & $30^{\circ} \mathrm{C} / 65 \% \mathrm{RH}$ & $30^{\circ} \mathrm{C} / 75 \% \mathrm{RH}$ \\
\hline 2006 & \multirow{2}{*}{\multicolumn{4}{|c|}{ ICH Q1F is withdrawn }} \\
\hline 2009 & & & & \\
\hline
\end{tabular}

Guidelines for stability testing of active pharmaceutical ingredients and pharmaceutical products provided by WHO.

The final draft was proposed in May 2005. The following guideline defines the stability data package for a drug substance or drug product that is sufficient for registration within the GCC Countries. ${ }^{6,8}$

General storage condition as per SFDA guidelines are as per Table 6 .

6. Chinese Pharmacopoeia: Chinese pharmacopeia in its Appendix XX provide 'Guidelines for the stability testing for the drug substance and preparations'.

\section{With drawal of ICH Q1F guideline}

Due to these differences in opinion regarding the storage condition for long-term stability testing of pharmaceutical drug substance and product among different regions of climatic Zone IV, ICH decided to withdraw the guideline Q1F and leave the definition of the storage condition in climatic zone III and IV to respective regions and WHO.

Q1F was withdrawn by ICH in year 2006.

\section{Explanatory Note on the Withdrawal of ICH Q1F for the ICH Website}

ICH Q1 F Stability Data Package for Registration Applications in Climatic Zones III and IV defined storage conditions for stability testing in countries located in Climatic Zones III (hot and dry) and IV (hot and humid), i.e. countries not located in the ICH regions and not covered by ICH Q1 A (R2) Stability Testing for New Drug Substances and Drug Products. ICH Q1 F described harmonized global stability testing requirements in order to facilitate access to medicines by reducing the number of different storage conditions. In the course of the discussions which led to the development of the guideline, WHO conducted a survey amongst their member states to find consensus on $30^{\circ} \mathrm{C} / 65 \% \mathrm{RH}$ as the long-term storage conditions for hot and humid regions. As no significant objection was raised in this survey, $30^{\circ} \mathrm{C} / 65 \%$, RH was defined as the long-term storage condition for Climatic Zone III/IV countries in ICH Q1F. The document was adopted by the ICH Steering Committee in February 2003 and subsequently implemented in the ICH regions.
However, based on new calculations and discussions, some countries in Climatic Zone IV have expressed their wish to include a larger safety margin for medicinal products to be marketed in their region than foreseen in ICH Q1F. As a consequence, several countries and regions have revised their own stability testing guidelines, defining up to $30^{\circ} \mathrm{C} / 75 \% \mathrm{RH}$ as the long-term storage conditions for hot and humid regions. Due to this divergence in global stability testing requirements, the ICH Steering Committee has decided to withdraw ICH Q1F and to leave definition of storage conditions in Climatic Zones III and IV to the respective regions and WHO. In assessing the impact of the withdrawal of ICH Q1F on intermediate testing conditions defined in ICH Q1A (R2), the decision was reached to retain $30^{\circ} \mathrm{C} / 65 \% \mathrm{RH}$. However, regulatory authorities in the $\mathrm{ICH}$ regions have agreed that the use of more stringent humidity conditions such as $30^{\circ} \mathrm{C} / 75 \% \mathrm{RH}$ will be acceptable should the applicant decide to use them. ${ }^{2}$

\section{Alternative provided by WHO}

Due to withdrawal of ICH Q1F guideline WHO decided to prepare a new guideline to exemplify the core stability data package required for the registration of active pharmaceutical ingredients (APIs) and finished products (FPPs), replacing the previous WHO guideline published in 1996. The WHO expert committee on specifications for pharmaceuticals preparations agreed in October 2006 in general to prepare this working document as a draft that could serve as a replacement for the WHO 'Guidelines for stability testing of pharmaceutical products containing well established drug substances in conventional dosage forms', and to include a list of long term stability conditions as required by WHO member states.

Summary of the journey of stability guidelines is as per Table 7

\section{CONCLUSION}

Considering the above-mentioned information, it can be concluded that in last few years there has been repetitive changes in long-term storage condition for testing of pharmaceutical product stability. 
The subject had become so sensitive that the decisions were revised under various influences and the same lead to withdrawal of ICH guideline Q1F. In the year 2009 WHO again played a leading role by providing an alternative for ICH Q1F and until date, this guideline has been followed without influence of any individual request.

\section{REFERENCES}

1. Singh S. Global Long Term Stability Testing Conditions: Position of India. Presentation.

2. Explanatory Note on the Withdrawal of ICH Q1F for the ICH Website [Internet]. $\mathrm{ICH} ; 2006$ [cited 20 December 2015]. Available from: http://www.ich.org/fileadmin/Public_Web_Site/ICH_Products/Guidelines/Quality/Q1F/Q1F_Explanatory_Note.pdf.

3. Stability testing of active pharmaceutical ingredients and finished pharmaceutica products [Internet]. 1st ed. ICH; 2009 [cited 21 December 2015].Availablefrom: http://www.ich.org/fileadmin/Public_Web_Site/ICH_Products/Guidelines/Quality/ Q1F/Stability_Guideline_WHO.pdf.

4. ASEAN Guideline on Stability Study of Drug Product [Internet]. 6th ed. 2013 [cited 25 December 2015]. Available from: http://www.hsa.gov.sg/content/dam/ HSA/HPRG/Western_Medicine/Overview_Framework_Policies/Guidelines_on_ Drug_Registration/ASEAN\%20STABILITY\%20GUIDELINE\%20(version\% 20 6.0).pdf.

5. REGIONAL GUIDELINE FORTHE WHO EASTERN MEDITERRANEAN REGION [Internet].2nded.2006 [cited23December2015].Availablefrom:http://www.who.
int/medicines/services/expertcommittees/pharmprep/QAS06_179_Stability GuidelineSept06.pdf.

6. The GCC Guidelines for Stability Testing of Drug Substances and Pharmaceutical Products EDITION TWO [Internet]. 2nd ed. 2007 [cited 22 December 2015]. Available from: http://sgh.org.sa/Portals/0/PDF/Books/Stability.pdf.

7. Official Mexican Standard NOM-073-SSA1-2005, Stability of Drugs and Medicine [Internet]. 1st ed. 2005 [cited 25 December 2015]. Available from: http:// pharmalytik.com/images/stories/PDF/mexico\%20nom-073-ssa1-2005\%20 -\%20english\%20corr.pdf.

8. The GCC Guidelines for Stability Testing of Drug Substances and Pharmaceutical Products EDITION TWO [Internet]. 2nd ed. 2007 [cited 24 December 2015]. Available from: http://www.ich.org/fileadmin/Public_Web_Site/ABOUT_ICH/Organisation/GCC/Topics_under_Harmonisation/Stability.pdf.

9. Stability testing of active pharmaceutical ingredients and finished pharmaceu tical products [Internet]. 1st ed. 2009 [cited 1 January 2016]. Available from: http://www.ich.org/fileadmin/Public_Web_Site/ICH_Products/Guidelines/Quality/Q1F/Stability_Guideline_WHO.pdf.

10. Dr. Kopp S. Stability Testing of Pharmaceutical Products In a global Environment [Internet]. 1st ed. 2006 [cited 9 January 2016]. Available from: http://www.who. int/medicines/areas/quality_safety/quality_assurance/RAJ2006WHOStability. pdf

11. Productos farmaceuticos. Estudios de estabilidad de medicamentos para uso humano [Internet]. $1^{\text {st }}$ ed. [cited 10 January 2016]. Available from: http:// www.ministeriodesalud.go.cr/empresas/normativas/DRS_Anexo_resolucion_20256_2010.pdf.

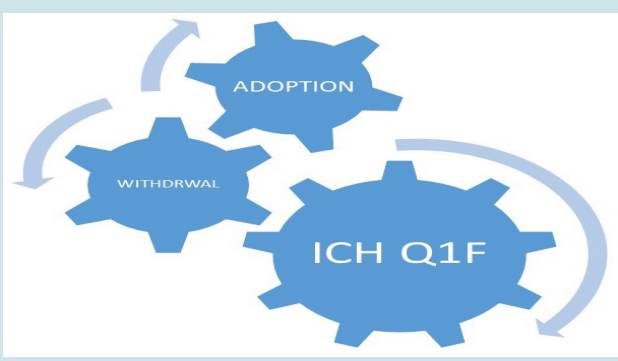

\section{PICTORIAL ABSTRACT}

\section{SUMMARY}

- ICH Q1 F guideline provided a stability data package for the registration applications of drug substance and drug product in Climatic Zones III (hot and dry) and IV (hot and humid).

- These guidelines were adopted by the ICH in February 2003 and subsequently implemented in the $\mathrm{ICH}$ regions.

- Due to some reasons the guidelines were withdrawn.

\section{ABOUT AUTHORS}

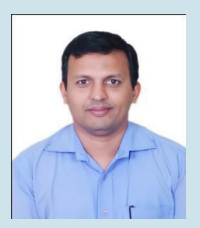

Muddukrishna B.S.: Is Assistant Professor-Senior scale in Department of Pharmaceutical Quality Assurance, Manipal College of Pharmaceutical Sciences, Manipal University. He teaches pharmaceutical analysis to undergraduate students and pharmaceutical quality assurance and management to post graduate students of Pharmacy

He has $16+$ years of total experience in academics, Research \& Development, Laboratory Operations \& Quality Assurance in an organization of high repute.

He has published several papers in journals of high repute and have presented papers in national and international conference.

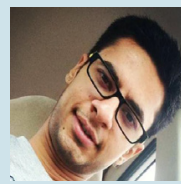

SIDDHARTH JADEJA B.: Is a student in department of pharmaceutical quality assurance in Manipal College of Pharmaceutical Sciences, Manipal University.

He has presented papers in national conferences. Presently he is doing his dissertation work in Syngene International Ltd, Biocon Park as Intern under the guidance of Muddukrishna B.S. 